\title{
Outcomes of surgical practice on tubo-ovarian abscess in an academic hospital
}

\author{
Burak Sezgin $\odot$, Melike Nur Akın $\odot$, Burcu Kasap $\odot$ \\ Department of Obstetrics and Gynecology, Sitkı Koçman University School of Medicine, Muğla, Turkey
}

\begin{abstract}
Objectives: We aimed to analyseour experience in the surgical management of tubo-ovarian abscess at a tertiary hospital.

Methods: Data from patients who underwent laparoscopy or laparotomyfor treatment of tubo-ovarian abscess were retrospectively analyzed. The clinical and surgical outcomes of patients with tubo-ovarian abscess were compared according to the applied surgical approach.

Results: The mean largest diameter of the abscess in the laparoscopy and laparotomy groups were similar $(p$ $=0.520)$. The mean day for total antibiotic use was significantly shorter in the laparoscopy group (10.00 \pm 4.37 day vs $17.91 \pm 6.59$ day; $p=0.002$ ). All cases in the laparotomy group needed to change the antibiotic regimen, but it was needed only in $28.58 \%$ of patients in the laparoscopy group. However, preoperative fever and pulse rate was significantly higher in laparotomy group than in the laparoscopy group $(p=0.004, p=$ 0.014; respectively). There was no statistical difference in terms of applied surgical procedure betweenthetwo groups. The most applied surgical procedure was abscess drainage in both of the groups $(71.42 \%, 90.90 \%$; respectively). The median operation time in patients with laparoscopy was statistically shorter than in patients with laparotomy (65.50 [58-93] minutes vs 84 [74-90] minutes, $p=0.048)$. In comparison of postoperative complications between two groups, there was no statistically significant difference. We observed statistically significant declination in white blood cell count and C-reactive protein values at the postoperative 7 th day in all patients $(p<0.001$ and $p<0.001$, respectively).
\end{abstract}

Conclusions: In terms of surgical approach for tubo-ovarian abscess, laparoscopy is more effective than laparotomy for shorter duration of postoperative antibiotic use, operation time and length of hospital stay.

Keywords: Laparoscopy, laparotomy, pelvic inflammatory disease, surgical approach, tubo-ovarian abscess

$\mathrm{T}$ ubo-ovarian abscess (TOA) is a complex infectious adnexial mass affecting the fallopian tubes and ovaries. It usually comes across as a sequelae of pelvic inflammatory disease (PID). Common clinical signs are adnexial mass, high fever, foul-smelling discharge, lower abdominal pain and high leukocyte counts. In addition, clinical presentations may vary. If the abscess ruptures, it can be life-threatening because of sepsis. Therefore, hospitalization is recommended to begin treatment immediately after the diagnosis of TOA [1-3].

In cases which developed TOA, an underlying PID is often found, but it is not a must. In recent years, new management schemes created by Centers for Disease Control and Prevention (CDC) in the investigation and treatment of sexually transmitted diseases have re- 
duced the incidence of TOA to $2.3 \%$ in patients with a history of PID [4]. However, patients with TOA still face serious complications such as chronic pelvic pain, deterioration of pelvic anatomy, risk of future ectopic pregnancy, infertility and recurrent PID.

Today, $70 \%$ of patients with TOA can be treated conservatively with improvements in broad spectrum antibiotics, imaging methods and drainage techniques $[5,6]$. If an unruptured TOA is detected, treatment with intravenous antibiotics may be initiated. However, $31 \%$ of these patients may require surgical intervention due to medical treatment failure. Although the classical initial treatment is antibiotic therapy, surgery may be required if rupture occurs or antibiotic treatment fails.

Today, surgical procedures such as abscess drainage, salpingectomy, salpingo-oophorectomy and hysterectomy can be performed with laparoscopy or laparotomy in patients who require surgery due to TOA. In addition, percutaneous drainage can be performed by the help of interventional radiology [7]. But there is no consensus on what is the optimal surgical treatment for the TOA. In this research, we aimed to investigate patients who treated surgically due to TOA in our clinic in terms of surgical approach.

\section{METHODS}

This study was conducted from May 2016 to May 2020. Ethical approval was obtained from the ethics committee for clinical research of Mugla Sitki Kocman University, School of Medicine, Mugla, Turkey. Data from patients who treated surgically for TOA were retrospectively analyzed. The diagnosis of TOA was established in patients who met the PID criteria in accordance with CDC criteria [8]. We extracted patients who underwent laparoscopy or laparotomy as inclusion criteria. Exclusion criterias were as follows; lack of medical records, malignancy suspicion or malignancy diagnosis. The essential data were retrieved from the patient files and hospital database records.

During this period, 30 patients treated surgically for TOA due to medical treatment failure by our experienced surgical team. Data from 4 (endometrial cancer (1), ovarian cancer (3)) patients with malignancy were excluded from the study. One patient with lack of hospital records was also excluded. A total of
14 patients with laparoscopy and 11 patients with laparotomy were included. The characteristic features of patients such as age, gravida, parity, weight, height, BMI (body mass index), any history related to normal parturition, caesarean and/or abortion, menopausal status, comorbidities (diabetes, hypertension), smoking, intrauterine device use, surgical approach (laparoscopy/laparotomy), surgical procedure (drainage/salpingectomy/salpingo-oophorectomy/hysterectomy), operation time, postoperative complications (bladder, ureter and bowel injury, postoperative ileus and venous thromboembolism), largest abscess diameter, vital signs (systolic blood pressure (SBP), diastolic blood pressure (DBP), pulse rate, and fever), preoperative and postoperative first and seventh day levels of biochemical parameters (hemoglobin, hematocrit, white blood cell count (WBC), platelet count and C-reactive protein), abscess culture (positivity/negativity), transfusion need (erythrocyte suspension), duration of preoperative and postoperative antibiotic treatment, and need of antibiotic regimen change were obtained from the hospital database.

The scheme of antibiotic treatment in cases diagnosed with TOA during the whole study length was identical and was followed in all patients. Medical treatment failure is defined as not to respond antibiotics within 48 or 72 hours after admission, progressive increase in $\mathrm{C}$-reactive protein, increasing fever and sign/symptoms of abscess rupture [9]. In cases of medical treatment failure, the surgery was performed either by laparoscopy or laparotomy. During the entire research length, our default surgical approach for patients who failed medical treatment was laparoscopy. Laparotomy was performed in selected patients with a history of multiple abdominal opertaions and deep pelvic endometriosis.

It has been checked that, all the blood samples taken from patients both 24 hours preoperatively and, $1^{\text {st }}$ and $7^{\text {th }}$ day postoperatively (hemoglobin, hematocrit, platelet, WBC count and C-reactive protein). The calculation parameters are in $\mathrm{g} / \mathrm{dL}, \%, \times 103 / \mu \mathrm{L}$, $\times 103 / \mu \mathrm{L}$ and $\mathrm{mg} / \mathrm{L}$, respectively.

The patients were grouped into the laparoscopy group $(n=14)$ and the laparotomy group $(n=11)$. Demographical features of patients were described. Preoperative and postoperative surgical outcomes were compared and analyzed. Abscess diameter were determined according to transvaginal/transabdominal ultra- 
sonography scan, abdominal computed tomography and magnetic resonance imaging examination (if performed) records as the biggest diameter of the measurement.

\section{Statistical Analysis}

The collected data were analyzed by using SPSS software, version 23. The data were expressed as the mean \pm SD and range for continuous or discrete variables, and categorical variables were reported as frequency and percentage. The significance of differences between the groups was determined using Independent samplesT-test (for normally distributed data) and Mann-Whitney U test (for non-normally distributed data). The Friedman's test, an alternative to the single factor variance analysis, was used for the not normally distributed data.All statistical comparisons were considered significant at a $p$ value of less than 0.05 .

\section{RESULTS}

The characteristics of the two groups of patients are documented in Table 1. No differences in demo- graphic variables and comorbidities appeared, and the average age of women in the two groups was similar (laparoscopy: $42.57 \pm 9.04$ vs laparotomy:42.09 \pm $13.98 ; p=0.918)$. A total $21.42 \%$ of the laparoscopy group and $27.27 \%$ of the laparotomy group had a history of caesarean section $(p=0.582)$. Prior abort history was present in $42.85 \%$ of the laparoscopy group and $45.45 \%$ of the laparotomy group $(p=0.903)$. There was no significant difference in the rates of smoking and intrauterine device usage between the groups.

The clinical and surgical outcomes of the two groups were compared and are reported in Table 2. The mean largest diameter of the abscess in the laparoscopy and laparotomy groups were similar (6.09 \pm 1.93 cmvs $6.99 \pm 4.74 \mathrm{~cm}, p=0.520)$. It was $6.48 \pm$ $3,40 \mathrm{~cm}$ in all patients who underwent surgery. The mean day for antibiotic use was $3.07 \pm 2.76$ days in laparoscopy group, preoperatively and it was $3.82 \pm$ 4.26 days in laparotomy group ( $p=0.601)$. The mean day for total antibiotic use was statistically significantly shorter in the laparoscopy group (10.00 \pm 4.37 day vs $17.91 \pm 6.59$ day; $p=0.002$ ). Four patients $(28.58 \%)$ in laparoscopy group and 7 patients $(63.63 \%)$ in the laparotomy group were needed trans-

Table 1. Demographic characteristics of the study population

\begin{tabular}{|c|c|c|c|c|}
\hline Variable & $\begin{array}{l}\text { Laparoscopy } \\
(n=14)\end{array}$ & $\begin{array}{l}\text { Laparotomy } \\
\quad(n=11)\end{array}$ & $\begin{array}{c}\text { Total } \\
(n=25)\end{array}$ & $p$ value \\
\hline Age (years) & $42.57 \pm 9.04$ & $42.09 \pm 13.98$ & $42.36 \pm 11.21$ & $0.918^{*}$ \\
\hline Weight (kg) & $74.14 \pm 10.83$ & $83.18 \pm 25.44$ & $78.12 \pm 18.82$ & $0.241^{*}$ \\
\hline Height (cm) & $163.42 \pm 6.46$ & $166.09 \pm 4.20$ & $164.60 \pm 5.64$ & $0.250^{*}$ \\
\hline BMI $\left(\mathrm{kg} / \mathrm{m}^{2}\right)$ & $28.51(25.08-31.16)$ & $29.76(26.03-31.64)$ & $28.72(25.71-31.18)$ & $0.584^{*}$ \\
\hline Gravidity (n) & $2.86 \pm 1.95$ & $2.27 \pm 1.67$ & $2.60 \pm 1.83$ & $0.439 *$ \\
\hline Parity (n) & $2.07 \pm 1.14$ & $1.45 \pm 1.63$ & $1.80 \pm 1.38$ & $0.278^{*}$ \\
\hline NSVD (n) & $2(0-3)$ & $2(0-3)$ & $1(0-3)$ & $0.075^{¥}$ \\
\hline Prior C/S, n(\%) & $3(21.42)$ & $3(27.27)$ & $6(24)$ & $0.582^{¥}$ \\
\hline Prior Abortus, n (\%) & $6(42.85)$ & $5(45.45)$ & $11(44)$ & $0.903^{¥}$ \\
\hline Smoking, n (\%) & $5(35.71)$ & $3(27.27)$ & $8(32)$ & $0.660^{*}$ \\
\hline IUD use, n (\%) & $7(50)$ & $3(27.27)$ & $10(40)$ & $0.259^{¥}$ \\
\hline Diabetes, n (\%) & $3(21.42)$ & $2(18.18)$ & $5(20)$ & $0.844^{\Psi}$ \\
\hline Hypertension, n (\%) & $4(28.57)$ & $3(27.27)$ & $7(28)$ & $0.944^{¥}$ \\
\hline
\end{tabular}

Data are shown as mean $\pm \mathrm{SD}^{*}$ or median $\left(25^{\text {th }}-75^{\text {th }}\right)^{\ddagger}$ or $\mathrm{n}(\%)$. BMI $=$ Body mass index, NSVD $=$ Normal spontaneous vaginal delivery, $\mathrm{C} / \mathrm{S}=$ Cesarean section, IUD $=$ Intrauterine device

*Independent sample t-test; ${ }^{\ddagger}$ Man-withney U test, Statistically significance: $p<0.05$ 
Table 2. Clinical and surgical characteristics of the study population

\begin{tabular}{|c|c|c|c|c|}
\hline Variable & $\begin{array}{l}\text { Laparoscopy } \\
(n=14)\end{array}$ & $\begin{array}{l}\text { Laparotomy } \\
\qquad(\mathrm{n}=11)\end{array}$ & $\begin{array}{c}\text { Total } \\
(n=25)\end{array}$ & $p$ value \\
\hline Abscess size (cm) & $6.09 \pm 1.93$ & $6.99 \pm 4.74$ & $6.48 \pm 3,40$ & $0.520 *$ \\
\hline Preop AR (day) (n) & $3.07 \pm 2.76$ & $3.82 \pm 4.26$ & $3.40 \pm 3.44$ & $0.601 *$ \\
\hline Total AR (day) (n) & $10.00 \pm 4.37$ & $17.91 \pm 6.59$ & $13.48 \pm 6.67$ & $0.002 *$ \\
\hline Transfusion need, n (\%) & $4(28.58)$ & $7(63.63)$ & $11(44 \%)$ & $0.086^{¥}$ \\
\hline$(+)$ Culture, n (\%) & $3(21.42)$ & $5(45.45)$ & $8(32)$ & $0.210^{¥}$ \\
\hline Change in AR, $n(\%)$ & $4(28.58)$ & $11(100)$ & $15(60)$ & $0.001^{¥}$ \\
\hline SBP (mm/Hg) & $110(102-130)$ & $110(90-120)$ & $110(95-125)$ & $0.558^{¥}$ \\
\hline DBP (mm/Hg) & $66.5(60-72.5)$ & $70(60-80)$ & $68(60-75)$ & $0.795^{¥}$ \\
\hline Pulse (beat/min) & $84.71 \pm 7.63$ & $92.64 \pm 7.08$ & $88.20 \pm 8.28$ & $0.014 *$ \\
\hline Fever $\left({ }^{0} \mathrm{C}\right)$ & $36.55(36.4-36.72)$ & $37.3(36.8-38.5)$ & $36.7(36.4-37.35)$ & $0.004^{¥}$ \\
\hline Drainage, $\mathbf{n}(\%)$ & $10(71.42)$ & $10(90.90)$ & $20(80)$ & $0.244^{¥}$ \\
\hline Salpingectomy, n (\%) & $6(42.85)$ & $3(27.27)$ & $9(36)$ & $0.441^{¥}$ \\
\hline SO, n (\%) & $6(42.85)$ & $5(45.45)$ & $11(44)$ & $0.902^{¥}$ \\
\hline Hysterectomy, n (\%) & $3(21.42)$ & $2(18.18)$ & $5(20)$ & $0.848^{¥}$ \\
\hline Operation time (minute) & $65.50(58-93)$ & $84(74-90)$ & $75(64-89)$ & $\mathbf{0 . 0 4 8}^{*}$ \\
\hline Bladder injury, n (\%) & 0 & $1(9.1)$ & $1(4)$ & $0.259^{¥}$ \\
\hline Bowel injury, n (\%) & 0 & 0 & 0 & \\
\hline Ureter injury, n (\%) & 0 & $1(9.1)$ & $1(4)$ & $0.259^{*}$ \\
\hline Ileus, n (\%) & 0 & 0 & 0 & \\
\hline Wound infection, n (\%) & 0 & $2(18.18)$ & $2(18.18)$ & $0.103^{*}$ \\
\hline VTE, n (\%) & 0 & 0 & 0 & \\
\hline
\end{tabular}

Data are shown as mean $\pm \mathrm{SD}^{*}$ or median $\left(25^{\text {th }}-75^{\text {th }}\right)^{*}$ or $\mathrm{n}(\%)$. LOHS $=$ Length of hospital stay, AR $=$ Antibiotic regimen, $\mathrm{SBP}=$ Systolic blood pressure, $\mathrm{DBP}=$ Diastolic blood pressure, $\mathrm{SO}=$ Salpingo-oophorectomy, $\mathrm{VTE}=$ Venous thromboembolism

*Independent sample t-test; ${ }^{\ddagger}$ Man-withney $\mathrm{U}$ test; Statistically significance: $p<0.05$

fusion requirement. Three of 14 patients $(21.42 \%)$ in laparoscopy group and five of 11 patients $(45.45 \%)$ in the laparotomy group had abscess culture positivity. All cases in the laparotomy group needed to change in antibiotic regimen, but only $28.58 \%$ of patients in the laparoscopy group needed antibiotic change. In terms of preoperative vital signs, SBP and DBP were recorded similar in either group. However, preoperative fever and pulse rate were statistically significantly higher in laparotomy group than in the laparoscopy group ( $p=0.004 ; p=0.014$, respectively).

There was no statistical difference in terms of applied surgical procedure between two groups. In the laparoscopy group, 10 patients underwent drainage, 6 patients underwent salpingectomy, 6 patients underwent salpingo-oophorectomy and 3 patients underwent hysterectomy procedures. In the laparotomy group, 10 patients underwent drainage, 3 patients underwent salpingectomy, 5 patients underwent salpingo-oophorectomy and 2 patients underwent hysterectomy.

The median operation time in patients with laparoscopy was statistically shorter than in patients with laparotomy (65.50 [58-93] minutes vs 84 [74-90] minutes, $p=0.048$ ). It was 75 [64-89] minutes in all patients who underwent surgery.

In comparison of postoperative complications between two groups, there was no statistically significant 
difference. No cases of postoperative complications, such as bladder injury, ureter injury, postoperative ileus, bowel injury, venous thromboembolism or wound infection, were recorded in the laparoscopy group. However, postoperative bladder injury in one patient $(9.1 \%)$, ureter injury in one patient $(9.1 \%)$ and postoperative wound infection in two patients $(18.18 \%)$ in the laparotomy group were recorded.

When we checked the hemoglobin, hematocrit and platelet counts in all surgical patients, there was no statistical difference between preoperative, postoperative 1 st and 7 th day values. However, we observed statistically significant decline in WBC count and Creactive values at the postoperative 7 th day in all patients ( $p<0.001$ and $p<0.001$, respectively) (Table 3 ).

In the laparotomy group, the operation was started laparoscopically in three patients but converted to laparotomy due to dense adhesions. The rate of conversion to laparotomy in cases initiated by laparoscopy was $21.43 \%$.

Of the 25 surgically treated patients, 4 of them had history of an intervention with in last three months of TOA formation (hysterosalpingography (1), therapeutic curettage (1), endometriosis operation (1) and caesarean section (1)). Pathology reports of 2 patients were proven as uterine abscess. Moreover, TOA was developed in the basement of endometriosis in two patients.

\section{DISCUSSION}

The present updated clinical guidelines suggest that medical management is offered as the first-line treatment approach for TOAs in hemodynamically stable patients with abscess size $<9 \mathrm{~cm}$ and no signs or symptoms of abscess rupture [4]. In our clinic, the initial treatment for hospitalized TOA patients is started with medical treatment in accordance with the newly updated clinical guidelines, and laparoscopy or laparotomy is performed in cases of antibiotic failure. Since interventional radiological methods are not activelyperformed in our hospital, we do not have such experience in this regard. In this study, we documented and compared the findings of patients who underwent surgery for TOA in our clinic. The main result of our study was that although there was no difference in abscess size in both groups, the duration of antibiotic use and antibiotic regimen change in hospital stay period were significantly lower in laparoscopy group than in laparotomy group. Moreover, postoperative $7^{\text {th }}$ dayWBC count and C-reactive protein values in all patients decreased significantly and it was observed that antibiotic attendance was important especially during the first 7 days of postoperative period.

The most important procedure recommended in patients with antibiotic failure is abscess drainage or removing the abscess focus. Here, the age of patient

Table 3. Preoperative, postoperative $1^{\text {st }}$ and $7^{\text {th }}$ day biochemical parameters of all patients

\begin{tabular}{|c|c|c|c|c|}
\hline Variable & $\begin{array}{c}\text { Preop } \\
\text { mean } \pm \text { SD } \\
(\min -m a x)\end{array}$ & $\begin{array}{c}\text { Postop } 1^{\text {st }} \text { day } \\
\text { mean } \pm \text { SD } \\
(\min -m a x)\end{array}$ & $\begin{array}{c}\text { Postop } 7^{\text {th }} \text { day } \\
\text { mean } \pm \text { SD } \\
(\min -m a x)\end{array}$ & $P$ value \\
\hline Hemoglobin (g/dL) & $\begin{array}{c}10.90 \pm 1.52 \\
(8.2-13.8)\end{array}$ & $\begin{array}{c}9.98 \pm 1.32 \\
(7.5-12.5)\end{array}$ & $\begin{array}{c}10.52 \pm 1.16 \\
(8.9-13)\end{array}$ & 0.227 \\
\hline Hematocrit (\%) & $\begin{array}{c}33.12 \pm 3.99 \\
(26.60-40.90)\end{array}$ & $\begin{array}{c}30.62 \pm 4.46 \\
(21-39)\end{array}$ & $\begin{array}{c}32.26 \pm 3.63 \\
(26.30-41.30)\end{array}$ & 0.053 \\
\hline $\mathrm{WBC}\left(\times 10^{3} / \mu \mathrm{L}\right)$ & $\begin{array}{l}14.63 \pm 4.49 \\
(5.93-24.02)\end{array}$ & $\begin{array}{l}13.55 \pm 4.88 \\
(5.30-24.60)\end{array}$ & $\begin{array}{l}10.32 \pm 5.02 \\
(4.90-28.30)\end{array}$ & $<0.001 *$ \\
\hline Platelet $\left(\times 10^{3} / \mu \mathrm{L}\right)$ & $\begin{array}{c}348.96 \pm 130.23 \\
\quad(171-658)\end{array}$ & $\begin{array}{c}349.48 \pm 102.50 \\
(178-543)\end{array}$ & $\begin{array}{c}418.40 \pm 174.21 \\
\quad(186-892)\end{array}$ & 0.261 \\
\hline CRP (mg/L) & $\begin{array}{c}188.76 \pm 126.06 \\
(20-463)\end{array}$ & $\begin{array}{c}168.80 \pm 108.01 \\
(8-372)\end{array}$ & $\begin{array}{c}46.20 \pm 44.82 \\
(1-148)\end{array}$ & $<0.001 *$ \\
\hline
\end{tabular}

Preop $=$ Preoperative, Postop $=$ Postoperative, $\mathrm{SD}=$ Standart deviation, $\mathrm{WBC}=$ White blood cell count

*Statistically significant difference. Friedman's Test $\left(\chi^{2}=39.65 ; p<0.05\right)$ 
and desire for fertility are effective in determining the type of surgery. $6 \%$ of failure rate has been reported in patients underwent only laparoscopic abscess drainage [10]. This is why aggressive surgical options can be considered especially in postmenopausal patients who have completed fertility [11]. There are some authors recommending laparoscopic approach to all patients with a desire for fertility [12]. In our clinic, we apply laparoscopy to all patients who have failed medical treatment and have a desire of fertility. We also applied salpingectomy, salpingo-oopherectomy, hysterectomy and drainage procedures to all of our patients alone or in combination. There was no difference in terms of applied surgical procedures between groups, but the most commonprocedure in both groups was abscess drainage. It is useful to emphasize that abscess drainage is an essential procedure in patients underwent surgery due to medical treatmen tfailure.

Patients received infertility treatment was related with higher incidence of surgical intervention and complicated clinical course, as evidenced by a shorter time interval from admission to surgery, higher rates of antibiotic failure, higher conversion rate from laparoscopy to laparotomy, increased pre- and postoperative complications rate, and a longer length of hospital stay [1]. In our study, there was a patient who received treatment for infertility. TOA was developed on the 15th day after hysterossalpingography application. The patient's surgery was started with laparoscopy but turned into laparotomy, and antibiotic regimen was needed to change twice. The clinical course of this patient was really more complicated and the duration of treatment took longer than other patients. Therefore, we can say that close follow-up of patients with a history of fertility treatment or prior interventional procedures is important for early diagnosis and treatment by means of TOA development.

Farid et al [13] reported in their study with 26 TOA cases underwent surgery that the average diameter of the TOA was found to be $7.85 \mathrm{~cm}$ [13]. In this group of patients, duration of hospitalization, inpatient antibiotic use and outpatient antibiotic use were 6.77 days, 5.71 days and 11.2 days, respectively. They concluded that in selected patients, concurrent abscess drainage may represent the most optimal treatment choice for patients who have WBC count greater than $16 \mathrm{~K}$ and abscess size greater than $5.18 \mathrm{~cm}$ at initial admission. The mean largest TOA diameter of all our surgical patients was $6.48 \mathrm{~cm}$ and the total duration of in patient antibiotic use was 13.46 days. In our country, there are many effective intravenous forms of antibiotics, but oral forms of these effective antibiotics do not exist or are difficult to reach. Therefore, many of TOA patients complete their 7-or 14-day treatment schemes in hospital. Long duration of inpatient antibiotic use in our study has been related with this condition.

In the literature, there are some data reported that medical treatment failure was related with fever and varying degrees of abscess size $(5.18 \mathrm{~cm}, 5.7 \mathrm{~cm}, 6$ $\mathrm{cm}, 7 \mathrm{~cm}, 8 \mathrm{~cm}$ ) [13-17]. It is also stated that these patients may be offered drainage as an initial treatment. In our study, the mean diameter of abscesses in both groups was found to be consistent with the literature. It is noteworthy that fever and pulse rate values of patients with laparotomy were significantly higher in preoperative period compared to patients with laparoscopy. In our analysis, the duration of antibiotic use in the laparotomy group was longer in the postoperative period than in the laparoscopy group. Moreover, all patients in the laparotomy group needed alteration in postoperative antibiotic regimen and this rate was significantly lower in laparoscopy applied patients. The impact of surgical approach on systemic inflammation is more in patients who underwent laparatomy than laparoscopy [18]. Moreover, Jacobi et al. [19] showed that inflammatory response was significantly higher in the laparotomy group compared to laparoscopy group. According to our data, lower systemic inflammatory response in laparoscopy may have positively affected the duration of postoperative antibiotic usage in laparoscopy applied patients. In fact, the higher systemic inflammatory response in the laparotomy group may have contributed to the alteration in antibiotic regimen during the postoperative period. Hence, laparoscopic approach with sufficient experience seems to be preferable to laparotomy in selected patients in TOA surgery.

There are some authors reported that pelvic malignancy can be found simultaneously with TOA [20]. So the investigation of concomitant pelvic malignancies such as the endometrium, ovary or cervix is very important in the presence of TOA, especially during the postmenopausal period. In their study, Yagur et al. [20] and Protopas et al. [21] detected pelvic malig- 
nancy in $1 / 22$ and $8 / 17$ of postmenopausal TOA patients concomitantly, respectively. In our study, one endometrial and three ovarian cancer cases were detected in postmenopausal TOA patients concomitantly. Although these cases were not included in our study, we want to emphasize here that it is very important to evaluate all organs in clockwise direction when exploring the pelvic cavity either by laparoscopy or laparotomy to aviod missed diagnosis of any pelvic malignancy in patients with TOA, especiallly in postmenopausal patients.

Güngördük et al. [22] stated in their study that surgical complications increase when the size of the abscess exceeds $7 \mathrm{~cm}$ in size. In their study, $63.15 \%$ of their cases were performed by laparotomy. We did not observe a correlation between abscess size and postoperative complications. In our study, although there was no statisticals ignificant difference between the two groups in terms of postoperative complications, all postoperative complications detected were belong to the laparotomy group. Here, it can be thought that the better visualization provided by laparoscopy during surgery may prevent postoperative complications.

\section{Limitations}

The strength of this study is that TOA diagnosis proven by histopathologically because all patients underwent surgery. Conversely, the retrospective design and limited number of patients to make subgroup analysis for surgical interventions are limitations of this study.

\section{CONCLUSION}

In conclusion, we evaluated the surgical approaches in cases with TOA in our clinic. Laparascopy should be the first choice of surgical approach in order not to lenghten the hospital stay, operation time and to maintain the initial antibiotic regimen.

\section{Conflict of interest}

The authors disclosed no conflict of interest during the preparation or publication of this manuscript.

\section{Financing}

The authors disclosed that they did not receive any grant during conduction or writing of this study.

\section{REFERENCES}

1. Fouks Y, Cohen Y, Tulandi T, Meiri A, Levin I, Almog B, et al. Complicated clinical course and poor reproductive outcomes of women with tubo-ovarian abscess after fertility treatments. J Minim Invasive Gynecol 2019;26:162-8.

2. Tao X, Ge SQ, Chen L, Cai LS, Hwang MF, Wang CL. Relationships between female infertility and female genital infections and pelvic inflammatory disease: a population-based nested controlled study. Clinics 2018;73:e364.

3. Fouks Y, Cohen A, Shapira U, Solomon N, Almog B, Levin I. Surgical intervention in patients with tubo-ovarian abscess: clinical predictors and a simple risk score. J Minim Invasive Gynecol 2019;26:535-43.

4. Workowski KA, Bolan GA; Centers for Disease Control and Prevention. Sexually transmitted diseases treatment guidelines, 2015. MMWR Recomm Rep 2015;64:1-137.

5. Brun JL, Graesslin O, Fauconnier A, Verdon R, Agostini A, Bourret A, et al. Updated French guidelines for diagnosis and management of pelvic inflammatory disease. Int J Gynaecol Obstet 2016;134:121-5.

6. Jaiyeoba O, Lazenby G, Soper DE. Recommendations and rationale for the treatment of pelvic inflammatory disease. Expert Rev Anti Infect Ther 2011;9:61-70.

7. Chan GMF, Fong YF, Ng KL. Tubo-ovarian abscesses: epidemiology and predictors for failed response to medical management in an Asian population. Infect Dis Obstet Gynecol 2019;2019:4161394.

8. Sexually Transmitted Diseases: Summary of 2015 CDC Treatment Guidelines. J Miss State Med Assoc 2015;56:372-5.

9. Ross J, Judlin P, Jensen J; International Union against sexually transmitted infections. 2012 European guideline for the management of pelvic inflammatory disease. Int J STD AIDS 2014;25:17.

10. Henry-Suchet J. Laparoscopic treatment of tubo-ovarian abscess: thirty years' experience. J Am Assoc Gynecol Laparosc 2002;9:235-7.

11. Hsiao SM, Hsieh FJ, Lien YR. Tubo-ovarian abscesses in postmenopausal women. Taiwan J Obstet Gynecol 2006;45:2348.

12.Rosen M, Breitkopf D, Waud K. Tubo-ovarian abscess management options for women who desire fertility. Obstet Gynecol Surv 2009;64:681-9.

13. Farid H, Lau TC, Karmon AE, Styer AK. Clinical characteristics associated with antibiotic treatment failure for tubo-ovarian abscesses. Infect Dis Obstet Gynecol 2016;2016:5120293.

14. Akkurt MÖ, Yalçın SE, Akkurt İ, Tatar B, Yavuz A, Yalçın Y, et al. The evaluation of risk factors for failed response to conservative treatment in tubo-ovarian abscesses. J Turkish Ger Gynecol Assoc 2015;16:226-30.

15. Venn A, Watson LF, Hemminki E, Healy D, Bruinsma FJ. Mortality in a cohort of IVF patients. Hum Reprod 2001;16:2691-6.

16. Dewitt J, Reining A, Allsworth JE, Peipert JF. Tuboovarian abscesses: is size associated with duration of hospitalization \& complications?. Obstet Gynecol Int 2010;2010:847041.

17. Topçu HO, Kokanali K, Güzel AI, Tokmak A, Erkilinç S, 
Ümit C, et al. Risk factors for adverse clinical outcomes in patients with tubo-ovarian abscess. J Obstet Gynaecol 2015;35:699702 .

18. Facy O, Paquette B, Orry D, Santucci N, Rat P, Rat P, et al. Inflammatory markers as early predictors of infection after colorectal surgery: the same cut-off values in laparoscopy and laparotomy? Int J Colorectal Dis 2017;32:857-63.

19.Jacobi CA, Ordemann J, Zieren HU, Volk HD, Bauhofer A, Halle E, et al. Increased systemic inflammation after laparotomy vs laparoscopy in an animal model of peritonitis. Arch Surg 1998;133:258-62.
20. Protopapas AG, Diakomanolis ES, Milingos SD, Rodolakis AJ, Markaki SN, Vlachos GD, et al. Tubo-ovarian abscesses in postmenopausal women: gynecological malignancy until proven otherwise? Eur J Obstet Gynecol Reprod Biol 2004;114:203-9. 21. Yagur Y, Weitzner O, Man-El G, Schonman R, Klein Z, Fishman A, et al. Conservative management for postmenopausal women with tubo-ovarian abscess. Menopause 2019;26:793-6.

22. Güngördük K, Guzel E, Asicioğlu O, Yildirim G, Ataser G, Ark C, et al. Experience of tubo-ovarian abscess in western Turkey. Int J Gynecol Obstet 2014;124:45-50. 